\title{
Eficácia de Controle de Plantas daninhas e toxicidade ao MILHO DA MisTURA DE FORAMSULFURON E IODOSULFURON Isoladamente ou em Associação com Atrazine e/OU CloRPIRIFós ${ }^{1}$
}

\author{
Weed Control Efficacy a nd Corn Toxicity of the Foramsulfuron and Iodosulfuron Mixture, Alone \\ or Combined with Atrazine and/or Chlorpyriphos
}

\begin{abstract}
TREZZI, M.M. ${ }^{2}$, FELIPPI, C.L. ${ }^{3}$, NUNES, A.L. ${ }^{4}$, CARNIELETO, C.E. ${ }^{3}$ e FERREIRA, A.R.J. ${ }^{3}$
RESUMO - Este trabalho constou de dois ensaios que avaliaram a toxicidade ao milho e a eficácia de controle de plantas daninhas dos herbicidas atrazine, da mistura foramsulfuron + iodosulfuron e do inseticida clorpirifós, isoladamente ou em mistura, aplicados em pós-emergência. Utilizou-se o delineamento de blocos ao acaso com quatro repetições. No primeiro ensaio, todos os tratamentos foram capinados e constaram de: atrazine $\left(3.000 \mathrm{~g} \mathrm{ha}^{-1}\right.$ de i.a.); atrazine + clorpirifós (3.000 + $225 \mathrm{~g} \mathrm{ha}^{-1}$ de i.a.); atrazine + foramsulfuron + iodosulfuron + clorpirifós $\left(2.250+15+1+225 ; 1.500+22,5+1,5+225\right.$; e $750+30+2+225$ g ha $^{-1}$ de i.a.); foramsulfuron + iodosulfuron ( $45+3 \mathrm{~g} \mathrm{ha}^{-1}$ de i.a.); foramsulfuron + iodosulfuron + clorpirifós $\left(45+3+225\right.$ g ha $^{-1}$ de i.a.); e testemunha sem aplicação de herbicidas. Já no segundo ensaio foram utilizados todos os tratamentos anteriores, com exceção da mistura de todos os produtos nas doses de $750+30+2+225 \mathrm{~g} \mathrm{ha}^{-1}$ de i.a., além dos respectivos tratamentos sem capina. Utilizou-se o cultivar de milho AG 3010 (híbrido duplo, superprecoce, tolerante a inibidores da ALS). Em 2002/2003, avaliou-se a toxicidade a milho e o rendimento, enquanto em 2003/2004 também foi avaliada a eficácia de controle de plantas daninhas. O uso de atrazine isoladamente ou em mistura com clorpirifós não gerou toxicidade às plantas de milho. A adição de clorpirifós à mistura foramsulfuron + iodosulfuron acentuou a injúria ao milho. A inclusão de atrazine simultaneamente à redução dos níveis de foramsulfuron + iodosulfuron permitiu reduzir em parte a injúria a plantas de milho, mantendo o controle de BRAPL e ampliando os níveis de controle de EPHHL.
\end{abstract}

Palavras-chave: sinergismo, mistura de produtos, inibidores da ALS, inibidores do FSII, rendimento de grãos.

ABSTRACT - Two trials evaluated corn toxicity and weed control efficacy of the herbicides atrazine, foramsulfuron, and iodosulfuron and the insecticide chlorpyriphos applied at postemergence alone or in mixture. A randomized complete block design was used with four replications. In the first trial, the treatments (weed free throughout cultivation) were: atrazine (3000g ha-1 of a.i.); atrazine + clorpyriphos (3000 + 225g ha $\mathrm{g}^{-1}$ of a.i.), atrazine + foramsulfuron + iodosulfuron + chlorpyriphos $\left(2,250+15+1+225 ; 1,500+22.5+1.5+225\right.$ and $750+30+2+225 \mathrm{~g} \mathrm{ha}^{-1}$ of a.i.); foramsulfuron+ iodosulfuron ( $45+3 \mathrm{~g} \mathrm{ha}^{-1}$ of a.i.); foramsulfuron + iodosulfuron + chlorpyriphos $\left(45+3+225 \mathrm{~g} \mathrm{ha}^{-1}\right.$ of a.i.), and a check without herbicides. In the second trial, the same treatments were used, except for atrazine + foramsulfuron + iodosulfuron + chlorpyriphos $\left(750+30+2+225 \mathrm{~g} \mathrm{ha}^{-1}\right.$ of a.i.), besides the same treatments above without weed cultivation. AG 3010 cultivar, a short-cycle double hybrid, tolerant to ALS herbicides, was used. During the 2002/2003 agricultural season, corn toxicity and grain yield were evaluated, while during 2003/2004, weed control efficacy was also evaluated. Atrazine alone or mixed with chlorpyriphos did not cause any toxicity to the corn plants. Chlorpiryphos + foramsulfuron and iodosulfuron association can increase corn plant injury. The inclusion of atrazine concomitant to foramsulfuron and iodosulfuron reduction allowed partial reduction of corn plant injury, maintaining BRAPL control and enhancing the level of EPHHL control.

Key words: $\quad$ synergism, herbicide mixtures, ALS-inhibitors, FSII-inhibitors, grain yield.

Recebido para publicação em 16/3/2005 e na forma revisada em 25/11/2005.

2 Professor Adjunto do Curso de Agronomia do CEFET/PR - Unidade Sudoeste, Via do Conhecimento km 01, Caixa Postal 571, 85503-390 Pato Branco-PR, <mtrezzi@ brturbo.com.br>; ${ }^{3}$ Acadêmico do Curso de Agronomia do CEFET/PR - Unidade Sudoeste; ${ }^{4}$ Mestrando do CPG em Fitotecnia da UFRGS. 


\section{INTRODUÇÃO}

Misturas de herbicidas são utilizadas freqüentemente pelos agricultores que cultivam milho, com o objetivo de aumentar o espectro de controle de plantas daninhas. Isso ocorre porque essas plantas apresentam-se, quase sempre, distribuídas de maneira heterogênea no campo, em populações mistas, que incluem, na maioria das vezes, várias espécies em pequena área.

O ideal é que misturas de herbicidas resultem em aumento da eficácia sobre plantas daninhas, redução da toxicidade a plantas cultivadas e redução das doses individuais, o que implicaria, também, menor efeito residual no solo e menor custo de controle (Ronchi et al., 2002). Associações de herbicidas com outros agroquímicos, como inseticidas e fungicidas, são bastante utilizadas para, especialmente, a redução do número de operações na lavoura, o que resulta em redução dos custos operacionais e da injúria causada à cultura pelo tráfego de máquinas. No entanto, herbicidas podem interagir sinergicamente com outras substâncias, potencializando a toxicidade a plantas cultivadas (Devine et al., 1993).

As triazinas e sulfoniluréias estão entre os grupos químicos de herbicidas mais utilizados atualmente no milho. O herbicida atrazine pertence ao grupo químico das triazinas, inibidor do transporte de elétrons no FSII (Fuerst \& Norman, 1991), sendo utilizado mais amplamente no controle seletivo em préemergência ou pós-emergência inicial das plantas daninhas dicotiledôneas e de algumas gramíneas no milho e em outras culturas (Rizzardi et al., 2004). O nicosulfuron e a mistura foramsulfuron + iodosulfuron, herbicidas do grupo químico das sulfoniluréias, são inibidores da enzima acetolactato sintase (ALS) aplicados em pós-emergência (Rizzardi et al., 2004); eles controlam um amplo espectro de plantas daninhas mono e dicotiledôneas (Comissão Estadual de Plantas Daninhas na Cultura do Milho, 2001).

A utilização de herbicidas inibidores da ALS, como o caso do nicosulfuron e da mistura foramsulfuron + iodosulfuron, pode causar toxicidade diferencial em híbridos de milho (Damião Filho et al., 1996), devido à diferente capacidade destes para metabolizá-los a compostos não-tóxicos (Brown, 1990; Bunting et al., 2004a).

A aplicação de inseticidas fosforados após os herbicidas inibidores da ALS ou com estes pode provocar injúria acentuada ao milho, mesmo a híbridos que lhe são tolerantes (Diehl et al., 1995). Esse fato é atribuído à redução da deposição de cera epicuticular pelo inseticida fosforado (Diehl et al., 1995). Esse tipo de inseticida poderia, também, reduzir a atividade da enzima citocromo P450, responsável pela metabolização dos herbicidas inibidores da ALS (Brown, 1990).

Acredita-se que o herbicida atrazine poderia substituir em parte a mistura foramsulfuron + iodosulfuron. Isso permitiria a redução do custo de controle de espécies daninhas, da toxicidade ao milho causada pelos inibidores da ALS e de possiveis perdas de rendimento de grãos. Como na literatura não se encontrou registro de ação sinérgica entre herbicidas inibidores do fotossistema II e inseticidas fosforados, a substituição parcial, referida anteriormente, poderia reduzir também a interação provocada pela mistura de inseticida fosforado e herbicidas inibidores da ALS.

Sobretudo, este trabalho teve como objetivo avaliar o potencial tóxico ao milho e o controle de plantas daninhas proporcionado por atrazine, foramsulfuron + iodosulfuron e clorpirifós, isoladamente ou em mistura.

\section{MATERIAL E MÉTODOS}

O trabalho constou de dois ensaios, realizados em dois anos agrícolas (2002/2003 e 2003/2004) na Área Experimental do Curso de Agronomia do CEFET/PR, Unidade Sudoeste, onde o solo é classificado como Latossolo Roxo Álico. O delineamento experimental utilizado foi de blocos ao acaso, com quatro repetições.

O híbrido utilizado nos ensaios foi o AG 3010 (híbrido duplo, superprecoce, considerado tolerante aos herbicidas inibidores da ALS). No primeiro ensaio, todos os tratamentos foram capinados (Tabela 1) aos 15 e 30 dias após a emergência do milho. No segundo, os tratamentos incluíram a utilização ou não de capinas (Tabela 1), nos mesmos períodos em que foram realizadas no primeiro ensaio. 
Tabela 1 - Tratamentos testados nos ensaios conduzidos em 2002/03 e 2003/04

\begin{tabular}{|c|c|c|c|c|}
\hline \multirow{2}{*}{$\mathrm{N}^{\mathrm{o}}$} & \multirow{2}{*}{ Manejo químico } & \multirow{2}{*}{$\begin{array}{l}\text { Níveis de i.a. } \\
\left(\mathrm{g} \mathrm{ha}^{-1}\right)\end{array}$} & \multicolumn{2}{|c|}{ Manejo mecânico } \\
\hline & & & $2002 / 03$ & $2003 / 04$ \\
\hline 1 & Atrazine $^{\underline{1} /}$ & 3.000 & Com capina & Com e sem capina \\
\hline 2 & Atrazine ${ }^{1 /}+$ clorpirifós & $3.000+225$ & Com capina & Com e sem capina \\
\hline 3 & Atrazine + foramsulfuron + iodosulfuron + clorpirifós ${ }^{21}$ & $2.250+15+1+225$ & Com capina & Com e sem capina \\
\hline 4 & Atrazine + foramsulfuron + iodosulfuron + clorpirifós ${ }^{2 /}$ & $1.500+22,5+1,5+225$ & Com capina & Com e sem capina \\
\hline 5 & Atrazine + foramsulfuron + iodosulfuron + clorpirifós ${ }^{2 /}$ & $750+30+2+225$ & Com capina & $-\frac{3}{3}$ \\
\hline 6 & Foramsulfuron + iodosulfuron ${ }^{2} /$ & $45+3$ & Com capina & Com e sem capina \\
\hline 7 & Foramsulfuron + iodosulfuron + clorpirifós $\mathrm{s}^{2 !}$ & $45+3+225$ & Com capina & Com e sem capina \\
\hline 8 & Testemunha sem herbicidas & & Com capina & Com e sem capina \\
\hline
\end{tabular}

${ }^{1 /}$ Adicionado óleo mineral Assist a $0,5 \%,{ }^{2 /}$ Adicionado surfatante Hoefix $\left(1,0 \mathrm{~L} \mathrm{ha}^{-1}\right) \mathrm{e}^{\underline{3} /}$ Ausente em 2003/04.

Em 2002/2003, as parcelas experimentais constaram de quatro linhas de $5 \mathrm{~m}$ de comprimento, espaçadas entre si de $0,7 \mathrm{~m}$, sendo consideradas como bordaduras as duas linhas laterais e $0,5 \mathrm{~m}$ de cada extremidade das linhas centrais, ou seja, a área útil foi de $5,6 \mathrm{~m}^{2}$. Foram colocadas duas a três sementes por cova, em área em pousio, com auxílio de saraquá, no dia 23.12.2002. Já em 2003/2004 as parcelas experimentais foram formadas por oito linhas, espaçadas entre si de 0,7 m, com $2,5 \mathrm{~m}$ de comprimento. As duas linhas das extremidades foram consideradas como bordaduras, bem como 0,5 $\mathrm{m}$ das extremidades de cada linha, ou seja, a área útil foi de $6,3 \mathrm{~m}^{2}$. A semeadura foi feita com semeadora de discos, em 9.10.2003, diretamente sobre as plantas secas de Brachiaria plantaginea. Nos dois ensaios, procedeu-se ao desbaste quando as plantas de milho estavam com três folhas completamente desenvolvidas, para atingir densidade de 60.000 plantas ha $^{-1}$.

A adubação de base foi efetuada com 40-80-80 kg ha-1 de $\mathrm{N}-\mathrm{P}_{2} \mathrm{O}_{5}-\mathrm{K}_{2} \mathrm{O}$ na linha de semeadura. Em cobertura, utilizaram-se $80 \mathrm{~kg} \mathrm{ha}^{-1}$ de $\mathrm{N}$ quando as plantas de milho estavam com seis folhas completamente desenroladas.

As aplicações dos herbicidas foram realizadas aos 27 dias após emergência nos dois ensaios (milho com nove e sete folhas completamente desenvolvidas, no primeiro e no segundo ensaio, respectivamente), com pulverizador pressurizado por $\mathrm{CO}_{2}$, bicos 11002 e volume de calda equivalente a $240 \mathrm{~L} \mathrm{ha}^{-1}$. Em 2003/2004, durante as aplicações dos herbicidas, infestavam a área predominantemente plantas de Brachiaria plantaginea (BRAPL, 398 plantas $\mathrm{m}^{-2}$, estádio de duas folhas a quatro afilhos, a maioria com quatro folhas), Bidens pilosa (BIDPI, 4 plantas $\mathrm{m}^{-2}$, com duas a quatro folhas) e Euphorbia heterophylla (EPHHL, 3 plantas $\mathrm{m}^{-2}$, com quatro a seis folhas). A aplicação dos produtos no primeiro ensaio ocorreu no período da manhã, com temperatura do ar entre 25 e $28{ }^{\circ} \mathrm{C}$, UR entre 72 e 65\%, na presença de vento moderado. No segundo ensaio, a aplicação ocorreu no período da tarde, com temperatura do ar entre 30 e $27^{\circ} \mathrm{C}$, UR entre 50 e $62 \%$, também sob vento moderado.

A toxicidade às plantas de milho foi determinada visualmente aos oito dias após a aplicação (DAA), no primeiro ensaio, e aos 12 DAA, no segundo ensaio, empregando-se uma escala visual de porcentagem, em que $0 \%$ correspondeu à ausência de sintomas e $100 \%$ à morte total das plantas. No primeiro ensaio determinou-se, também, a altura das plantas aos 15 e 42 DAA. Em 2003/04, a eficácia de controle de BRAPL, BIDPI e EPHHL também foi avaliada com a escala visual de porcentagem, aos 12 e 38 DAA. Foi determinado o rendimento pela pesagem dos grãos colhidos na área útil da parcela, corrigiu-se o teor de água dos grãos para 13\% e converteram-se os valores obtidos para hectare.

Os dados obtidos foram submetidos à análise de variância e, quando o efeito de tratamentos foi significativo, procedeu-se à comparação de médias pelo teste de Duncan a $5 \%$ de probabilidade. 


\section{RESULTADOS E DISCUSSÃO}

\section{Toxicidade ao milho}

A utilização do herbicida atrazine isoladamente ou em mistura com o inseticida clorpirifós não causou toxicidade ao milho ou ela foi muito baixa, nos dois ensaios, em relação à testemunha capinada (Tabela 2). López-Ovejero et al. (2003) verificaram elevada seletividade de atrazine + óleo vegetal para milho, pois esse tratamento não reduziu o comprimento da espiga, o número de folhas, o número de grãos por fileira da espiga e nem a massa de 1.000 grãos de milho. Conseqüentemente, o rendimento desse tratamento foi semelhante ao da testemunha capinada.

A mistura foramsulfuron + iodosulfuron (45 + 3 g ha $^{-1}$ de i.a.), com ou sem adição do inseticida clorpirifós, causou mais toxicidade do que atrazine (3.000 $\mathrm{g} \mathrm{ha}^{-1}$ de i.a.) isoladamente ou em mistura com inseticida fosforado, nos dois ensaios (Tabela 2). No entanto, a toxicidade da mistura dos inibidores da ALS foi 150\% maior em 2002/03 que em 2003/ 2004. Como nos dois ensaios utilizou-se o mesmo híbrido de milho, as diferenças podem ser devido ao estádio de desenvolvimento das plantas em que foram aplicados os tratamentos. Esse fato pode ter influenciado a absorção e metabolização dos herbicidas pelo milho. As injúrias ao milho com aplicações de foramsulfuron em estádio de seis ou nove folhas completamente desenvolvidas foram maiores do que no estádio de quatro folhas (Bunting et al., 2004b). A toxicidade ao milho de outro inibidor da ALS, nicosulfuron, no estádio de nove folhas completamente desenvolvidas foi maior do que nos estádios de três e seis folhas (Spader \& Vidal, 2001). A aplicação de nicosulfuron no estádio de oito folhas completamente desenvolvidas afetou características determinantes da prolificidade, em relação à aplicação em plantas com quatro folhas, mas não interferiu na duração dos estádios fenológicos do milho (López-Ovejero et al., 2003).

O aumento dos níveis de atrazine simultaneamente à redução da mistura foramsulfuron + iodosulfuron resultou em decréscimo da toxicidade ao milho, em 2002/03, em comparação ao uso da mistura sem adição de atrazine, com ou sem adição do inseticida (Tabela 2). Como a injúria ao milho causada por foramsulfuron + iodosulfuron sem adição de atrazine foi menor em 2003/04 do que em 2002/03, sua diminuição com a adição de atrazine não foi significativa. A adição de atrazine à mistura foramsulfuron + iodosulfuron não teve influência na altura de plantas (15 e 42 DAA), em relação à mistura sem atrazine, exceto quando à mistura de inibidores da ALS foi adicionado o inseticida fosforado (Tabela 2).

Tabela 2 - Toxicidade aos 8 (2002/03) e aos 12 DAA (2003/04) e altura do milho aos 15 e 42 DAA (2002/03), determinadas em tratamentos capinados

\begin{tabular}{|c|c|c|c|c|}
\hline \multirow{2}{*}{ Tratamento $^{\underline{1}}$} & \multicolumn{2}{|c|}{$\begin{array}{l}\text { Toxicidade ao milho } \\
\text { (\%) }\end{array}$} & \multicolumn{2}{|c|}{ Altura $(\mathrm{cm})$} \\
\hline & 8 DAA & $12 \mathrm{DAA}$ & $15 \mathrm{DAA}$ & 42 DAA \\
\hline Atrazine (3000) & $0,5 \mathrm{e}^{\mathrm{3} /}$ & $2,2 \mathrm{bc}$ & $136,5 \mathrm{a}$ & $213,2 \mathrm{a}$ \\
\hline Atrazine + Clorpirifós $(3000+225)$ & $0,0 \mathrm{e}$ & $1,7 \mathrm{bc}$ & $139,7 \mathrm{a}$ & $213,0 \mathrm{a}$ \\
\hline Atrazine + Foramsulfuron + Iodosulfuron + Clorpirifós $(2250+15+1+225)$ & $8,7 \mathrm{~d}$ & $3,2 \mathrm{abc}$ & $122,7 \mathrm{~b}$ & $204,7 \mathrm{~b}$ \\
\hline Atrazine + Foramsulfuron + Iodosulfuron + Clorpirifós $(1500+22,5+1,5+225)$ & $11,7 \mathrm{c}$ & $3,5 \mathrm{ab}$ & $126,3 \mathrm{~b}$ & $205,7 \mathrm{~b}$ \\
\hline Atrazine + Foramsulfuron + Iodosulfuron + Clorpirifós $(750+30+2+225)$ & $14,0 \mathrm{bc}$ & -4 & $121,7 \mathrm{~b}$ & $205,2 \mathrm{~b}$ \\
\hline Foramsulfuron + Iodosulfuron ${ }^{2}(45+3)$ & $15,0 \mathrm{~b}$ & $6,0 \mathrm{a}$ & $120,0 \mathrm{bc}$ & $200,2 \mathrm{~b}$ \\
\hline Foramsulfuron + Iodosulfuron ${ }^{2}+$ Clorpirifós $(45+3+225)$ & $19,2 \mathrm{a}$ & $6,5 \mathrm{a}$ & $112,7 \mathrm{c}$ & $198,5 \mathrm{c}$ \\
\hline Testemunha sem aplicação de herbicida & $0,0 \mathrm{e}$ & $0,0 \mathrm{c}$ & $139,7 \mathrm{a}$ & $213,0 \mathrm{a}$ \\
\hline
\end{tabular}

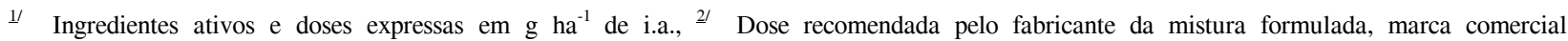
Equip plus, ${ }^{3 /}$ Médias de tratamentos seguidas da mesma letra, na coluna, não diferem estatisticamente entre si pelo teste de Duncan a $5 \%$ e ${ }^{4 /}$ Ausente em 2003/04 
É comum observar injúria acentuada causada pela adição de inseticida fosforado a inibidores da ALS mesmo em híbridos de milho que lhe são tolerantes. Esse fenômeno é atribuído à redução da deposição de cera epicuticular pelo inseticida, o que resulta em aumento da absorção desses herbicidas (Diehl et al., 1995), ou à interferência do clorpirifós na atividade da enzima citocromo P450, responsável pela metabolização desses herbicidas em milho (Brown, 1990). Por isso, recomenda-se intervalo mínimo de sete dias entre a aplicação da mistura formulada foramsulfuron+iodosulfuron e a de inseticida fosforado.

\section{Eficácia no controle de plantas daninhas}

Os melhores controles de BRAPL e BIDPI com os tratamentos de herbicidas foram, respectivamente, de 73 e $65 \%$, inaceitáveis na prática (Tabela 3). O melhor controle de BRAPL foi de $64 \%$, obtido com foramsulfuron + iodosulfuron $\left(45+3 \mathrm{~g} \mathrm{ha}^{-1}\right.$ de i.a.). $\mathrm{Em}$ Carambeí-PR, Penckowski et al. (2004) utilizaram a mesma associação e doses, obtendo níveis de controle de BRAPL de 99\%. Variações nos níveis de controle podem ocorrer em função de vários fatores, como condições de ambiente e estádio de desenvolvimento das plantas daninhas. No presente ensaio, a elevada densidade de plantas de BRAPL provavelmente dificultou a interceptação dos herbicidas e, conseqüentemente, contribuiu para redução nos niveis de controle de plantas daninhas.

Não houve diferenças entre os níveis de controle das plantas daninhas (Tabela 3), nem entre as médias da matéria seca total delas (Tabela 4), quando se empregou foramsulfuron + iodosulfuron (independentemente do uso de clorpirifós), em comparação à mistura desses inibidores da ALS com atrazine. Em geral, esses tratamentos demonstraram maior eficácia de controle de BRAPL e BIDPI que atrazine isoladamente ou em mistura com o inseticida fosforado (Tabela 3). A ação sistêmica de foramsulfuron + iodosulfuron pode favorecer o controle de plantas daninhas em áreas em que a densidade delas é elevada, em comparação com herbicidas com translocação mais limitada, como atrazine. Foramsulfuron e iodosulfuron translocam-se tanto pelo xilema quanto pelo floema (Vencill, 2002), com maior probabilidade de atingir as regiões meristemáticas das plantas, tornando o controle mais eficaz e evitando rebrota.

O tratamento de atrazine em mistura com foramsulfuron + iodosulfuron + clorpirifós $\left(2.250+15+1+225 \mathrm{~g} \mathrm{ha}^{-1}\right.$ de i.a. $)$ foi o único que, aos 12 e 38 DAA, proporcionou níveis de controle de EPHHL aceitáveis (90 e 88\%). Essa proporção entre inibidores da ALS e inibidor do FSII proporciona controle adequado de EPHHL já emergida (Tabela $3-12$ DAA) e também exerce controle sobre novos fluxos emergentes dessa espécie (Tabela 3 - 38 DAA).

\section{Rendimento de grãos}

Em 2002/03, o uso de atrazine ou de sua associação com o inseticida fosforado não influenciou o rendimento de grãos, em comparação à testemunha (Tabela 4). A aplicação da mistura foramsulfuron + iodosulfuron, com ou sem adição do clorpirifós, em plantas com nove folhas expandidas (2002/03) resultou em redução média de $20 \%$ do rendimento, em relação à testemunha capinada. Isso ocorreu por causa da toxicidade da mistura às plantas de milho, porquanto o efeito de competição não ocorreu devido à capina de todas as parcelas. A adição de atrazine à mistura de herbicidas e/ou a redução das doses de foramsulfuron + iodosulfuron atenuaram em parte o efeito deletério dos inibidores da ALS sobre o rendimento de grãos (Tabela 4). Esses resultados são similares aos obtidos por López-Ovejero et al. (2003), os quais verificaram que a aplicação de inibidor da ALS em milho com oito folhas expandidas reduziu o número de fileiras por espiga, o número de grãos por fileira e o peso de 1.000 grãos, com conseqüente menor rendimento de grãos. Bunting et al. (2004b) recomendaram que as aplicações de foramsulfuron fossem efetuadas antes do estádio de seis folhas expandidas, para evitar efeitos negativos sobre o rendimento de grãos.

A pequena injúria das plantas causada pelos herbicidas no segundo ensaio (2003/04), em que os tratamentos foram aplicados no estádio de sete folhas expandidas (Tabela 2), refletiu rendimentos de grãos similares entre os tratamentos capinados (Tabela 4). O uso de atrazine apenas, ou sua associação com clorpirifós, nos tratamentos sem capina,

Planta Daninha, Viçosa-MG, v. 23, n. 4, p. 653-659, 2005 
resultou em redução de rendimentos de 47,5 e $34,5 \%$ em relação a esses tratamentos químicos, porém com capina. Esse fato é explicado pelos baixos níveis de controle de plantas daninhas que se conseguiu com atrazine, principalmente da BRAPL (Tabela 3). Os rendimentos dos tratamentos sem capina da mistura foramsulfuron + iodosulfuron, com ou sem inseticida, e os da combinação da atrazine com foramsulfuron + iodosulfuron
$(1.500+22,5+1,5)$ não diferiram significativamente dos respectivos tratamentos capinados (Tabela 4). No entanto, a média de rendimento de grãos dos tratamentos sem capina em que foram incluídos foramsulfuron + iodosulfuron, com ou sem atrazine, foi de $7.050 \mathrm{~kg} \mathrm{ha}^{-1}$, enquanto os respectivos tratamentos capinados renderam $8.184 \mathrm{~kg} \mathrm{ha}^{-1}$ (Tabela 4), diferença de 13,9\%, causada pelo controle menos eficiente de plantas daninhas.

Tabela 3 - Eficácia de controle sobre Brachiaria plantaginea (BRAPL), Bidens pilosa (BIDPI) e Euphorbia heterophylla (EPHHL) aos 12 e 38 DAA, em 2003/2004

\begin{tabular}{|c|c|c|c|c|c|c|}
\hline \multirow[b]{2}{*}{ Tratamento $^{\underline{1}}$} & \multicolumn{6}{|c|}{ Eficácia de controle sobre espécies daninhas (\%) } \\
\hline & $\begin{array}{l}\text { BRAPL } 12 \\
\text { DAA }\end{array}$ & $\begin{array}{l}\text { BRAPL } 38 \\
\text { DAA }\end{array}$ & $\begin{array}{l}\text { EPHHL } 12 \\
\text { DAA }\end{array}$ & $\begin{array}{l}\text { EPHHL } 38 \\
\text { DAA }\end{array}$ & $\begin{array}{l}\text { BIDPI } 12 \\
\text { DAA }\end{array}$ & $\begin{array}{l}\text { BIDPI } 38 \\
\text { DAA }\end{array}$ \\
\hline Testemunha sem capina & $0 \mathrm{e}^{3 /}$ & $0 \mathrm{~d}$ & $0 \mathrm{e}$ & $0 \mathrm{~d}$ & $0 \mathrm{~d}$ & $0 \mathrm{e}$ \\
\hline Atrazine (3000) & $28 \mathrm{~d}$ & $20 \mathrm{c}$ & $65 \mathrm{c}$ & $61 \mathrm{c}$ & $50 \mathrm{~b}$ & $49 \mathrm{bc}$ \\
\hline Atrazine + Clorpirifós $(3.000+225)$ & $22 \mathrm{~d}$ & $25 \mathrm{c}$ & $46 d$ & $54 \mathrm{c}$ & $30 \mathrm{c}$ & $18 \mathrm{~d}$ \\
\hline $\begin{array}{l}\text { Atrazine + Foramsulfuron + Iodosulfuron + } \\
\text { Clorpirifós }(2.250+15+1+225)\end{array}$ & $63 \mathrm{bc}$ & $55 \mathrm{~b}$ & $90 \mathrm{~b}$ & $88 \mathrm{ab}$ & $58 \mathrm{~b}$ & $56 \mathrm{bc}$ \\
\hline $\begin{array}{l}\text { Atrazine + Foramsulfuron + Iodosulfuron + } \\
\text { Clorpirifós }(1.500+22,5+1,5+225)\end{array}$ & $73 \mathrm{~b}$ & $70 \mathrm{~b}$ & $82 \mathrm{~b}$ & $68 \mathrm{c}$ & $61 \mathrm{~b}$ & $58 \mathrm{bc}$ \\
\hline Foramsulfuron + Iodosulfuron ${ }^{2}(45+3)$ & $64 \mathrm{bc}$ & $60 \mathrm{~b}$ & $44 \mathrm{~d}$ & $71 \mathrm{bc}$ & $62 \mathrm{~b}$ & $65 \mathrm{~b}$ \\
\hline $\begin{array}{l}\text { Foramsulfuron + Iodosulfuron }{ }^{2 /}+\text { Clorpirifós } \\
(45+3+225)\end{array}$ & $60 \mathrm{c}$ & $64 \mathrm{~b}$ & $35 \mathrm{~d}$ & $65 \mathrm{c}$ & $65 \mathrm{~b}$ & $43 \mathrm{c}$ \\
\hline Testemunha capinada & $100 \mathrm{a}$ & $100 \mathrm{a}$ & $100 \mathrm{a}$ & $100 \mathrm{a}$ & $100 \mathrm{a}$ & $100 \mathrm{a}$ \\
\hline
\end{tabular}

${ }^{1 /}$ Ingredientes ativos e doses expressas em $\mathrm{g} \mathrm{ha}{ }^{-1}$ de i.a.; ${ }^{2 /}$ Dose recomendada pelo fabricante da mistura formulada, marca comercial Equip plus; $\mathrm{e}^{\frac{3 /}{}}$ Médias seguidas da mesma letra na coluna não diferem estatisticamente entre si pelo teste de Duncan a 5\%.

Tabela 4 - Matéria seca total de plantas daninhas (MS), determinada aos 58 DAA, em 2003/2004, e rendimento de grãos de milho em 2002/03 e 2003/04

\begin{tabular}{|c|c|c|c|}
\hline \multirow[t]{2}{*}{ Tratamentos ${ }^{1 /}$} & \multirow{2}{*}{$\begin{array}{c}\mathrm{MS} \\
\left(\mathrm{g} \mathrm{m}^{-2}\right)\end{array}$} & \multicolumn{2}{|c|}{$\begin{array}{l}\text { Rendimento de grãos } \\
\qquad\left(\mathrm{kg} \mathrm{ha}^{-1}\right)\end{array}$} \\
\hline & & $2002 / 03$ & $2003 / 04$ \\
\hline Atrazine (3.000) capinada & $-\frac{3}{=}$ & $5.463 \mathrm{ab}$ & $8.240 \mathrm{a}$ \\
\hline Atrazine + Clorpirifós (3.000 + 225) capinada $-m \ldots$ & - & $5.270 \mathrm{abc}$ & $7.495 \mathrm{ab}$ \\
\hline Atrazine + Foramsulfuron + Iodosulfuron + Clorpirifós $(2.250+15+1+225)$ capinada & - & $4.518 \mathrm{c}$ & $8.331 \mathrm{a}$ \\
\hline Atrazine + Foramsulfuron + Iodosulfuron + Clorpirifós $(1.500+22,5+1,5+225)$ capinada & - & $5.089 \mathrm{abc}$ & $\begin{array}{ll}8.273 \mathrm{a} \\
8.6\end{array}$ \\
\hline Atrazine + Foramsulfuron + Iodosulfuron + Clorpirifós $(750+30+2+225)$ capinada & - & $4.919 \mathrm{abc}$ & -- \\
\hline Foramsulfuron + Iodosulfuron ${ }^{21}(45+3)$ capinada & - & $4.818 \mathrm{bc}$ & $8.069 \mathrm{ab}$ \\
\hline Foramsulfuron + Iodosulfuron ${ }^{21}+$ Clorpirifós $(45+3+225)$ capinada & - & $4.626 \mathrm{c}$ & $8.063 \mathrm{ab}$ \\
\hline Testemunha capinada $\quad-1+n$ & - & $5.685 \mathrm{a}$ & $7.877 \mathrm{ab}$ \\
\hline Atrazine (3.000) sem capina & $43,3 \mathrm{a}^{4 /}$ & - & $4.323 \mathrm{~cd}$ \\
\hline 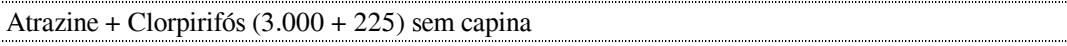 & $54,7 \mathrm{a}$ & - & $4.911 \mathrm{~cd}$ \\
\hline Atrazine + Foramsulfuron + Iodosulfuron + Clorpirifós $(2.250+15+1+225)$ sem capina & $12,2 \mathrm{~b}$ & - & $6.150 \mathrm{bcd}$ \\
\hline Atrazine + Foramsulfuron + Iodosulfuron + Clorpirifós $(1.500+22,5+1,5+225)$ sem capina & $5,7 \mathrm{~b}$ & - & $7.831 \mathrm{ab}$ \\
\hline Foramsulfuron + Iodosulfuron ${ }^{2}(45+3)$ sem capina & $14,2 \mathrm{~b}$ & - & $6.373 \mathrm{abc}$ \\
\hline Foramsulfuron + Iodosulfuron ${ }^{2}+$ Clorpirifós $(45+3+225)$ sem capina & $12,8 \mathrm{~b}$ & - & $7.847 \mathrm{ab}$ \\
\hline Testeminha sem capina & $47,6 \mathrm{a}$ & - & $2.984 \mathrm{de}$ \\
\hline
\end{tabular}

${ }^{1 /}$ Ingredientes ativos e doses expressas em g ha ${ }^{-1}$ de i.a.; ${ }^{2 /}$ Dose plena da mistura formulada, marca comercial Equip plus; ${ }^{3 /}$ Determinação não efetuada; $\mathrm{e}^{4 /}$ Médias de tratamentos seguidas da mesma letra na coluna não diferem estatisticamente entre si pelo teste de Duncan a $5 \%$. 
De modo geral, os resultados permitem concluir que a adição de inseticida fosforado à mistura de foramsulfuron e iodosulfuron pode acentuar a injúria ao milho. A inclusão de atrazine simultaneamente à redução de foramsulfuron + iodosulfuron permite reduzir em parte a injúria a plantas de milho, mantendo o controle sobre BRAPL e ampliando os niveis de controle de EPHHL.

\section{LITERATURA CITADA}

BROWN, H. M. Mode of action, crop selectivity, and soil relations of the sulfonylurea herbicides. Pest. Sci., v. 29, p. 263-281, 1990.

BUNTING, J. A.; SPRAGUE, C. L.; RIECHERS, D. E. Physiological basis for tolerance of corn hybrids to foramsulfuron. Weed Sci., v. 52, p. 711-717, 2004a.

BUNTING, J. A.; SPRAGUE, C. L.; RIECHERS, D. E. Corn tolerance as affected by the timing of foramsulfuron applications. Weed Technol., v. 18, p. 757-762, 2004 b.

COMISSÃO ESTADUAL DE PLANTAS DANINHAS NA CULTURA DO MILHO - CEPD. Manejo integrado de plantas daninhas. In: MATZENAUER, R. et al. (Orgs.) Indicações técnicas para a cultura do milho no RS. Porto Alegre: FEPAGRO, 2001. p. 92-101.

DAMIÃO FILHO, C. F.; MÔRO, F. V.; TAVEIRA, L. R. Respostas de híbridos de milho a nicosulfuron. 1- Aspectos biológicos e da produção. Planta Daninha, v. 14, p. 3-13, 1996.
DEVINE, M.; DUKE, S.; FEDTKE, C. Phisiology of herbicide action. Englewood Cliffs: Prentice Hall, 1993. 441 p. Cap. 13: Inhibition of amino acid byosynthesis.

DIEHL, K. E. et al. Effect of soil organic matter on the interaction between nicosulfuron and terbufos in corn (Zea mays). Weed Sci., v. 43, p. 306-311, 1995.

FUERST, P.; NORMAN, M. A. Interactions of herbicides with photosinthesis electron transport. Weed Sci., v. 39, p. 458-464, 1991.

LÓPEZ-OVEJERO, R. F. et al. Seletividade de herbicidas para a cultura de milho (Zea mays) aplicados em diferentes estádios fenológicos da cultura. Planta Daninha, v. 21, p. 413-419, 2003.

PENCKOWSKI, L. H. et al. Controle de poáceas através do herbicida foramsulfuron+iodosulfuron-methyl na cultura de milho. B. Inf. CPD, v. 10, p. 127, 2004.

RIZZARDI, M. A.; KARAM, D.; DA CRUZ, M. B. Manejo e controle de plantas daninhas em milho e sorgo. In: VARGAS, L.; ROMAN, E. S. (Eds.) Manual de manejo e controle de plantas daninhas. Bento Gonçalves: Embrapa Uva e Vinho, 2004. p. 571-594.

RONCHI, C. P. et al. Misturas de herbicidas para o controle de plantas daninhas do gênero Commelina. Planta Daninha, v. 20, p. $311-318,2002$.

SPADER, V.; VIDAL, R. A. Seletividade e dose de injúria econômica de nicosulfuron aplicado em diferentes estádios de desenvolvimento da cultura do milho. Ci. Rural, v. 31, p. 929-934, 2001. 